\title{
بطاقة الدفع الإكتروني في القانون الجزائري
}

Cet article porte sur les moyens

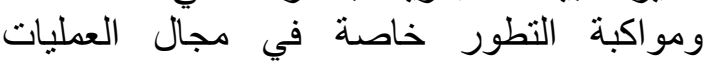
de paiement électroniques. On a

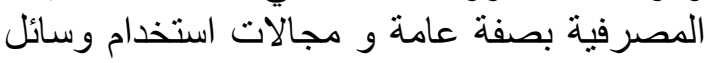
entamé notre étude par la définition de la carte de paiement

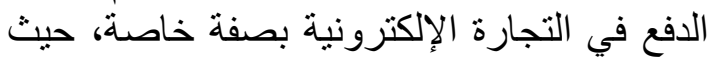
électronique, puis on a abordé le

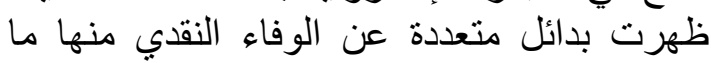

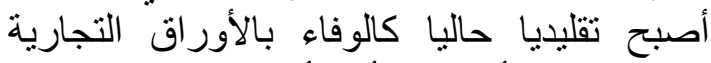

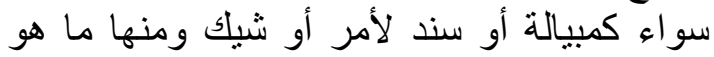
service concepteur de cette dernière, et enfin répertorié les types de cartes concevables. Nous

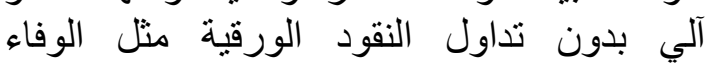

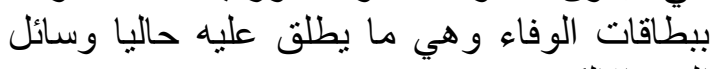
nous sommes également intéressés aux relations juridiques relatives à la conception et la mise en œuvre الدفع الإلكتروني. (1)

Plastic وظهرت البطاقات البلاستيكية de la carte de paiement électronique.

Cards المتحدة حوالي عام 1914 عندما أصدرت الصات

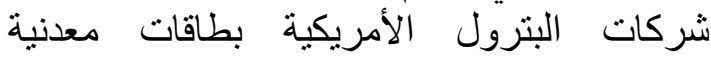

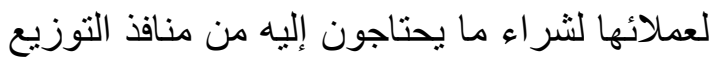
التابعة لها و تسوية هذه المشتريات في نهاية كل 


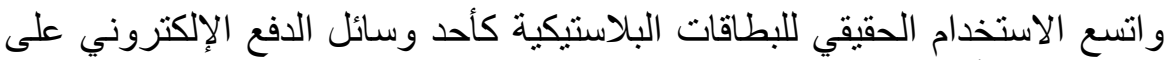

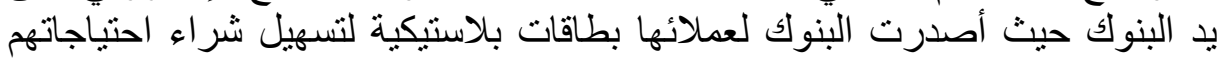

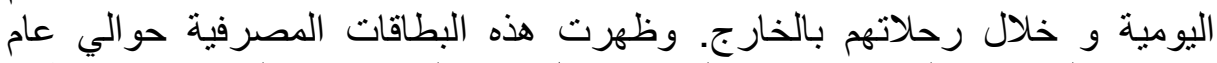

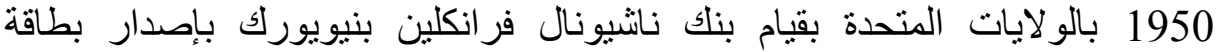
National Credit Card Club دينرز كلوب Diners du club وانتشر استخدام هذه فئ البطاقات خاصة فئات البطاقات

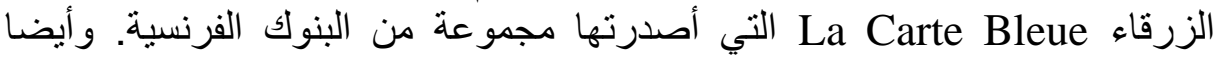
البطاقات الخضراء La Carte Verte و أعقب ذلك ظهور كثير من البطاقات في

فرنسا مثل الكارت الذهبي La Carte dorée الصادر عن اتحاد الفنادق. (2) ثم انتشرت وسائل الدفع الإلكتروني إلى باقي الدول الأوروبية و انجلترا. ولم

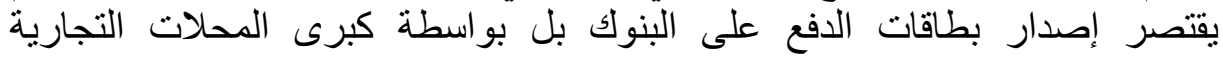

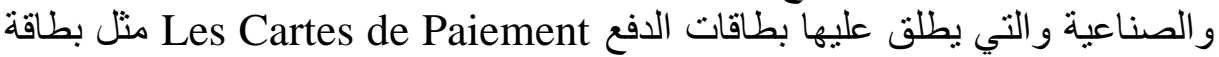

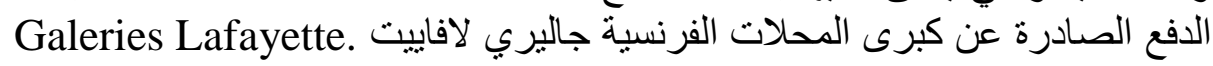
هذا وقد نص المشرع الجزائري في بداية الأمر على بطاقات الدفع من خلال قانون

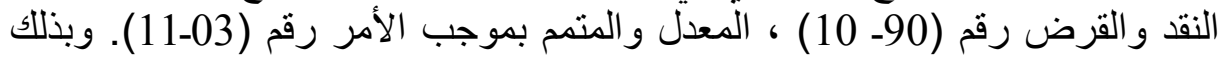

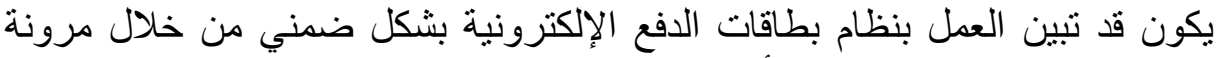

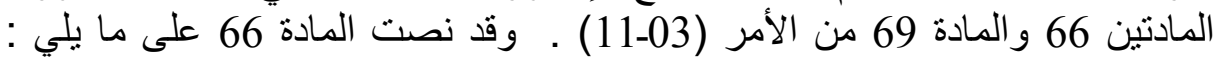

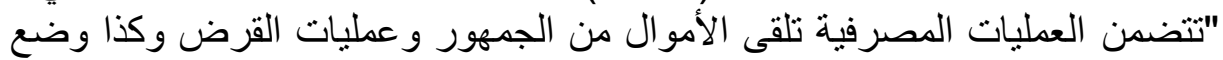
وسائل الدفع تحت تصرف الزبائن و إدارة هذه الوسائلت".

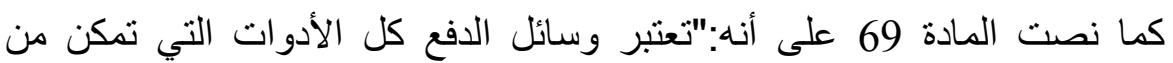
تحويل أمو ال مهما يكن السند أو الأسلوب التهني المستعمل".

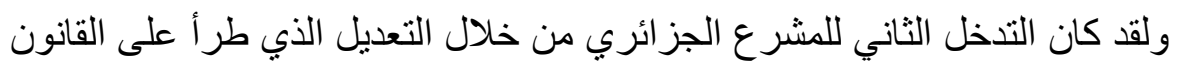

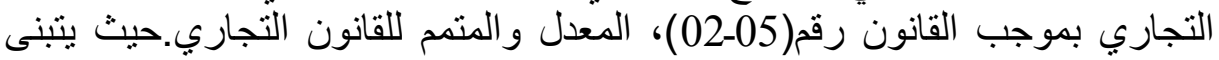

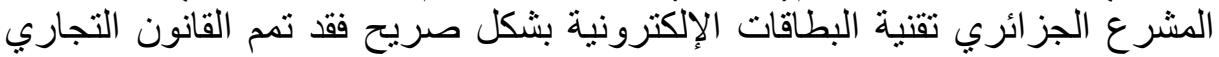

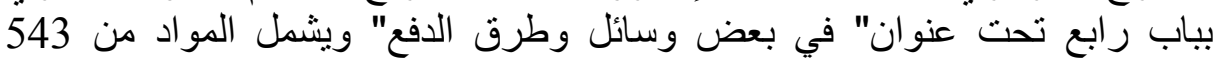

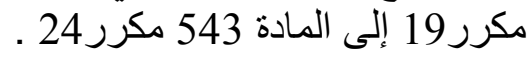

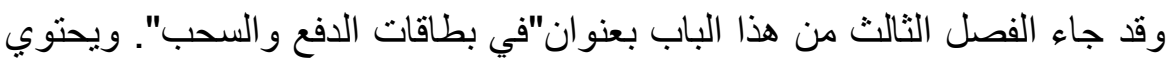

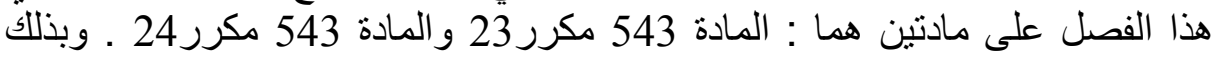
يكون المشرع الجزائري قد أرسى أحكام خاصة بادين البطاقات الإلكترونية.

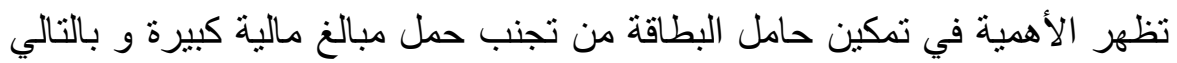

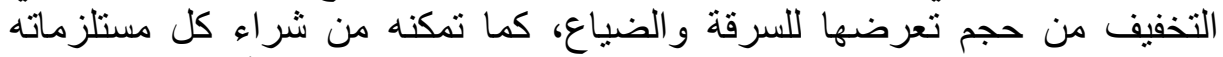
بالرغم من عدم توفر النقود اللازمة للدفع النقدي الفوري سواء داء داخل أو خارج وطنه. 
كما تفيد التجار الذين يقبلون التعامل بها فهي تمكنهم من زيادة حجم المبيعات

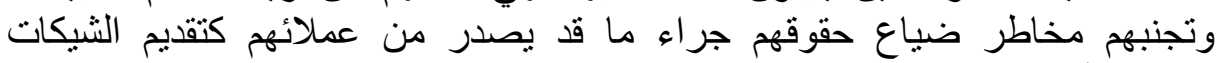
المزورة أو شيكات بدون رصنيد.

وتبقى البنوك المصدرة لهذه البطاقات الأكثر استفادة منها حيث يغري الأفر اد بفتح

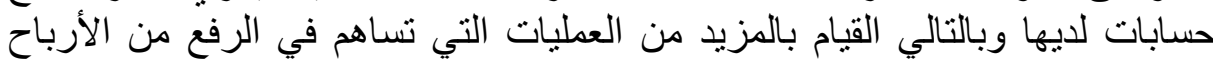
لايها .

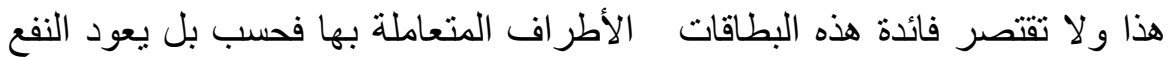

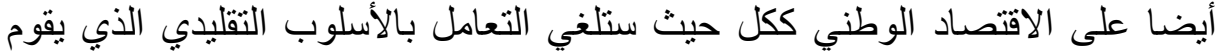

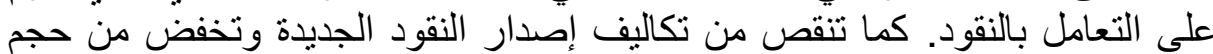
النقد المصدر النعامل

ويطرح هذا الموضوع مجموعة من الإشكاليات القانونية أهمها : مفهوم هذه

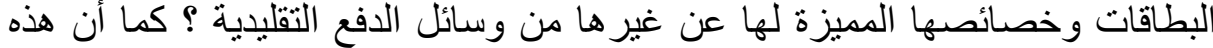

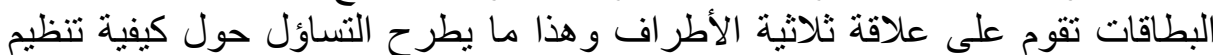

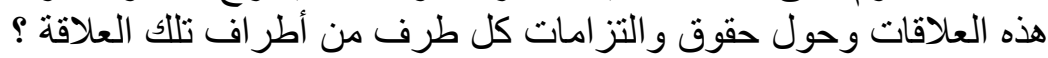

كل هذه الإشكاليات سنحاول الإجابة عنها معتمدين في ذللك على مناهج البحث

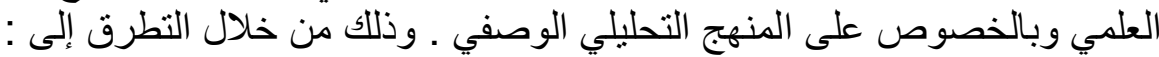
التعريف ببطاقات الدفع الإلكتروني والجهة المصدر لها أنو اعها ثم النظام القانوني

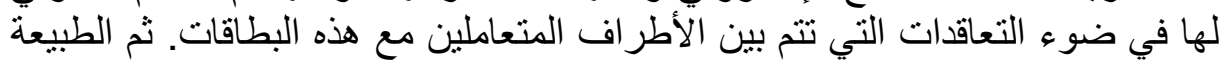

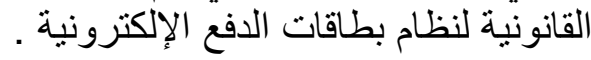

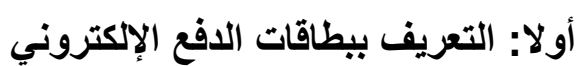

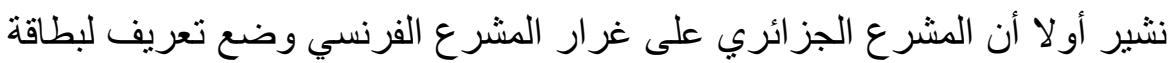

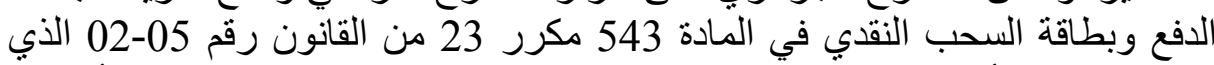

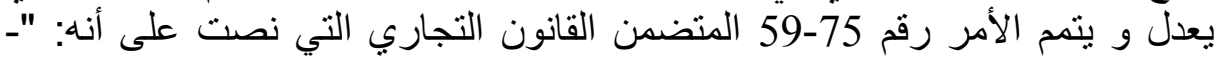

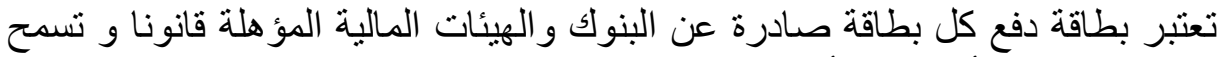
لصاحبها بسحب أو تحويل أمو ال. تعلة

- عتبر بطاقة سحب كل بطاقة صادرة عن البنوك أو الهيئات المالية المؤهلة قانونا و تسمح لصناحبها فقط بسحب أمو ال". بالنسبة للفقه (3) يمكن تعريفها من الناحية القانونية ومن الناحية الثكلية و من

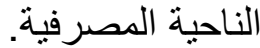

- مأما من الناحية الثكلية يمكن تعريفها بأنها قطعة بلاستيكية بأبعاد قياسية

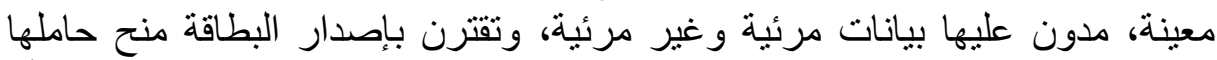

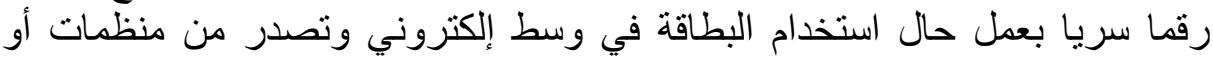


بنوك ذات ثقة تصمن تعاملات العميل في شبكة التعامل بالبطاقة و بموجبها تمكنه من

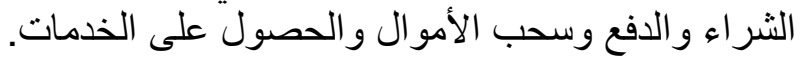

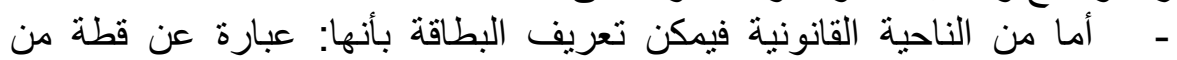

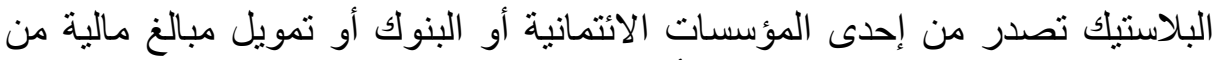

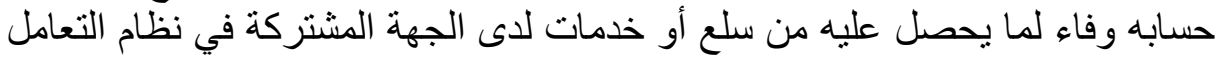

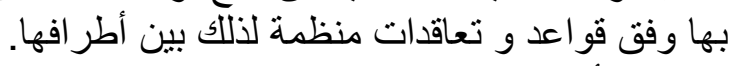

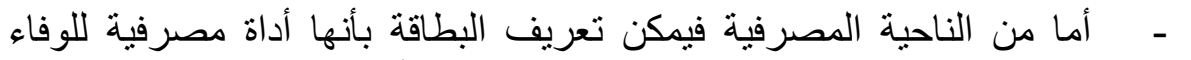

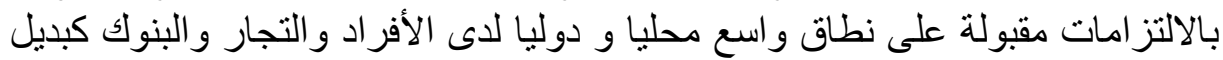

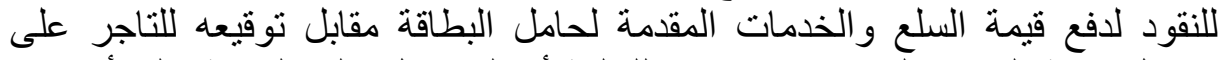

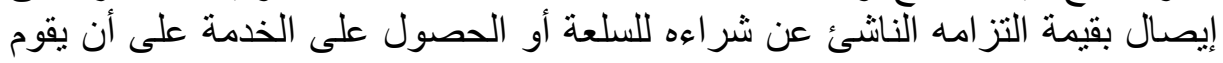

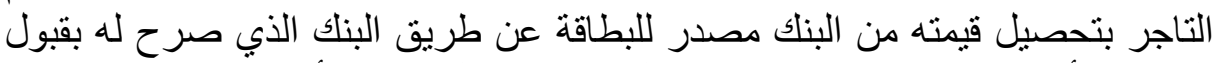

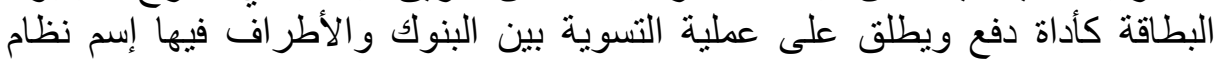

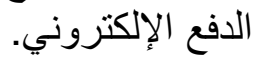

\section{ثانيا:الجهة المصدرة لبطاقات الافع الإكتروني:}

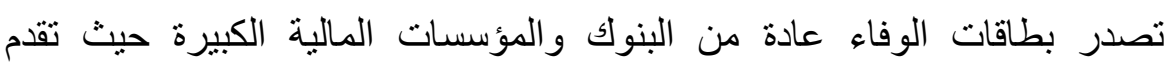

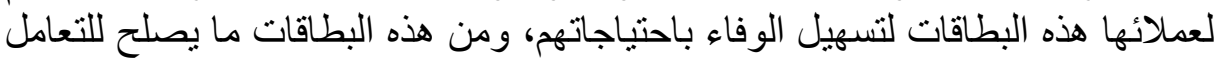

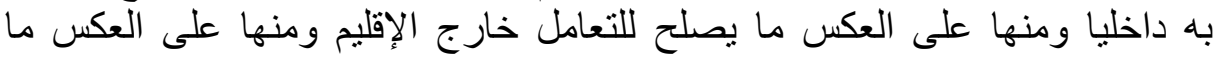

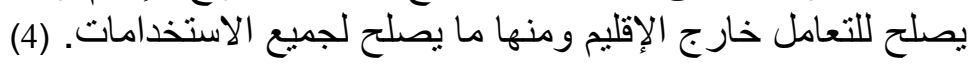

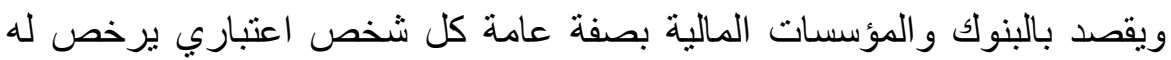
القانون أو البنك المركزي ممارسة عمليات البنوك كلهات البها أو بعضها.

وتصدر بطاقات الدفع الإلكتروني أيضا من المؤسسات التجارية الكبرى، يستخدمها

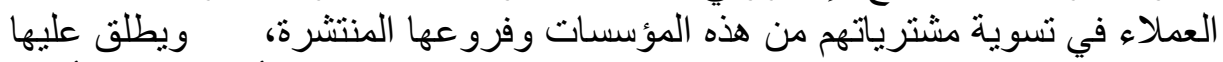
حيث تقوم متاجر السلسلة CARDS STORE DEPARTEMENT STORES

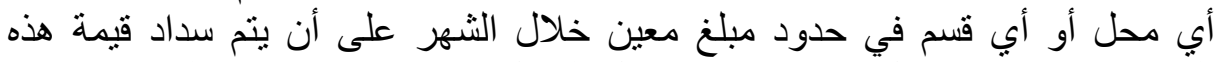

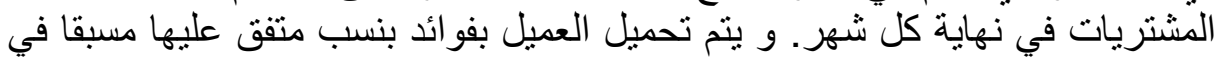

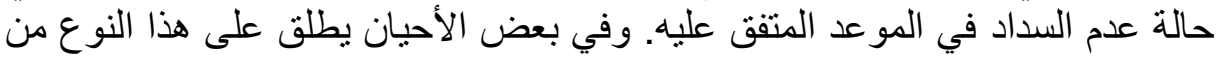

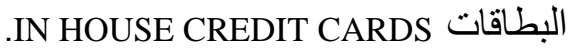

KEMART- ومن أثنر هذه المتاجر في أوروبا والولايات المتحدة وكندا محلات HOLYDAY-DATENS-REMBOW-CANADA.

كما قد تصدر هذه البطاقات من جهات أخرى كالنوادي الخاصة كما هو الثأن بالنسبة لبطاقات دينرز كلوب. و التكييف القانوني لبطاقات الدفع الالكتروني التي تصدر ها المحلات التجارية 
و التي لها فروع في أنحاء البلاد لتمكين عملائها من الوفاء بمشترياتهم لاى هذه

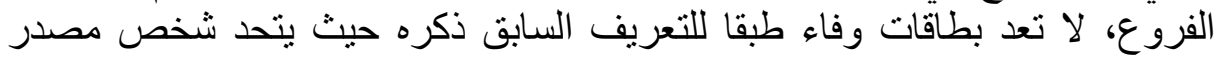
البطاقة و التاجر ، وإن كانت تمثنل إحدى وسائل الدفع إلكترونيا.

و هذه البطاقات لا تعد من أعمال البنوك أو المؤسسات المالية السابق الإشارة إليها

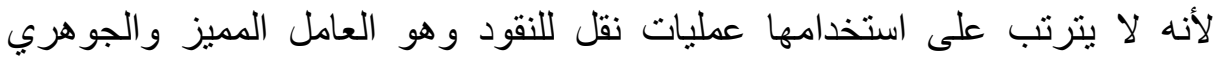

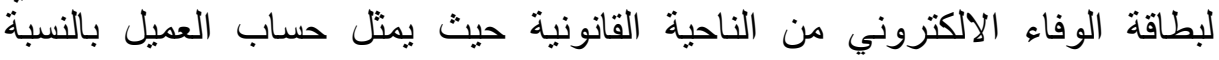

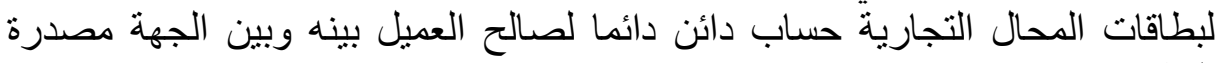

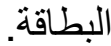

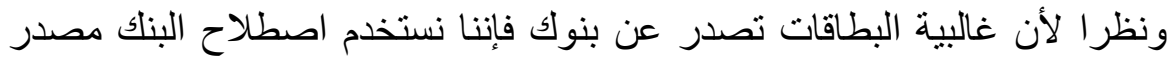

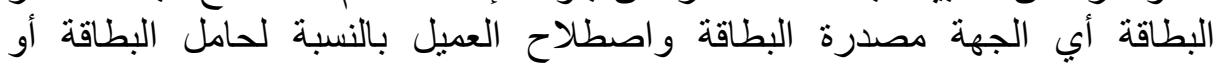

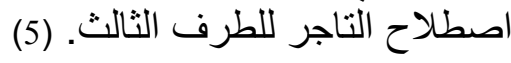
ثالثا: أنواع بطاقات الدفع الإكتروني:

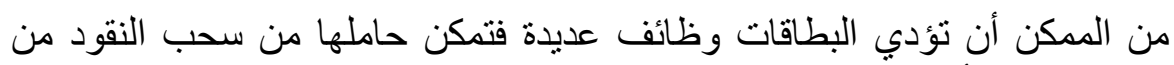

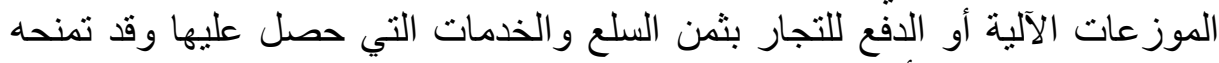

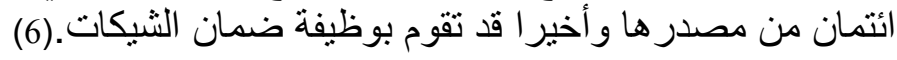
و الأصل في البطاقات (حاليا) هو تجميع كل الوظائف في بطاقة واحدة ولهي و الاستثناء هو أداء البطاقة لوظيفة واحدة.

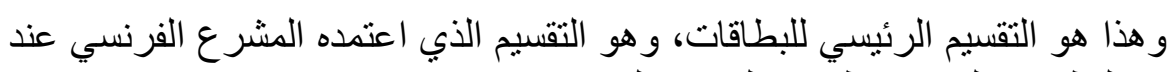

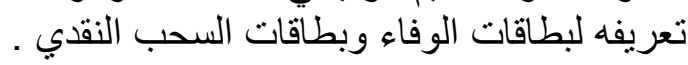
أولا: بطاقات سحب النقود:

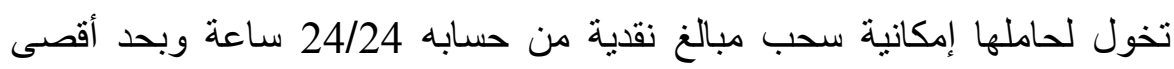
متفق عليه بين مصدر البطاقة وحاملها.

وقد عرفها المشرع الفرنسي (هو نفس تعريف المشرع الجزائري) وفقا للتعديل

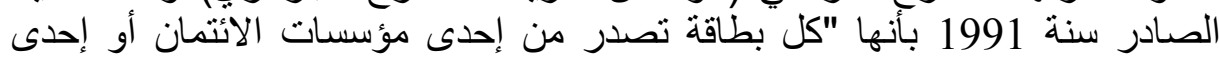

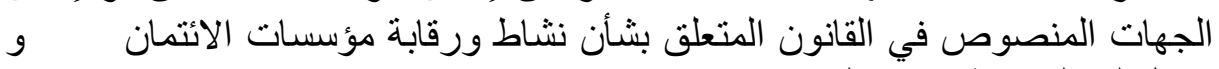
تخول لعاملها فقط سحب النقود في التون النوان

ثانيا: بطاقات تستخدم لسحب النقود و الثراء من التجار (بطاقة الدفع)

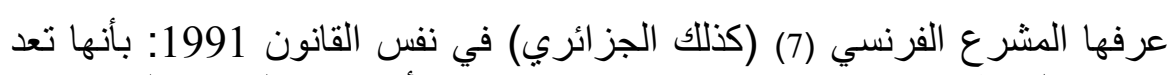

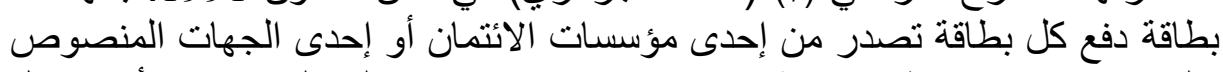

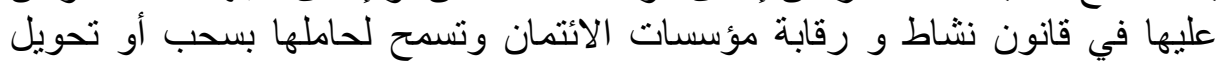
نقود من حسابه. 
ما يلاحظ من هذا التعريف أنه تجاهل عنصر هام قد يربط ببعض البطاقات و هو

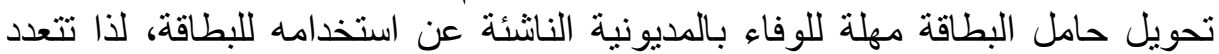

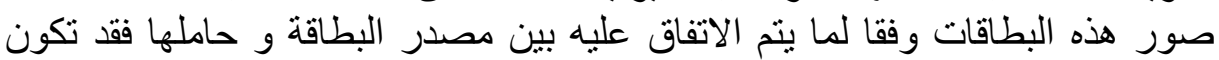

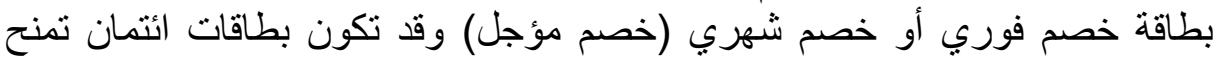

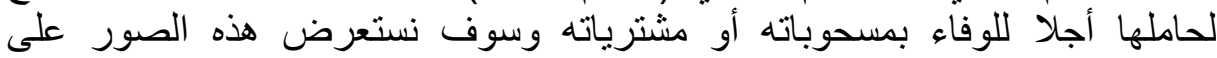
التوالي:

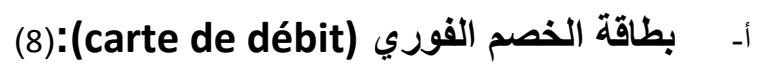

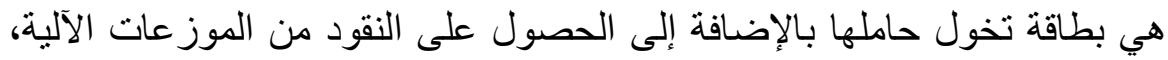

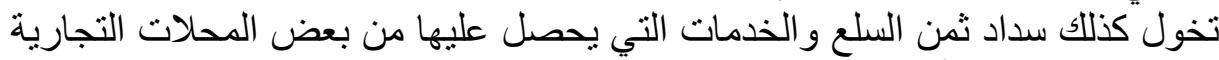

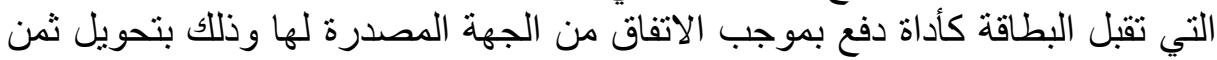

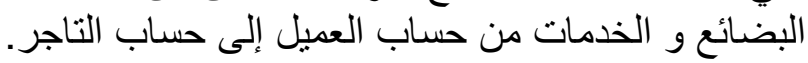

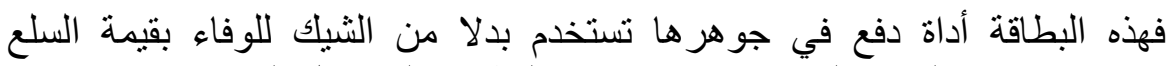

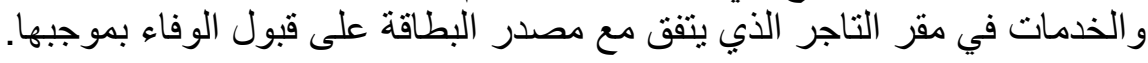

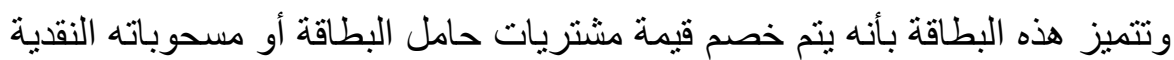

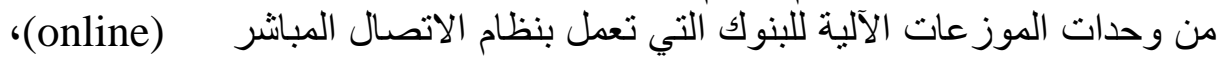

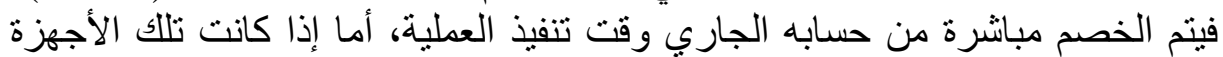
تعمل بنظام الاتصال غير المباشر (offline) فإنه يتم الخصم فور ورود الإشعار أو الفاتورة للبنك النك

إذن الأمر هنا يتعلق بإمكانية توفر لاى التجار أجهزة التحويل الإلكتروني في نقاط

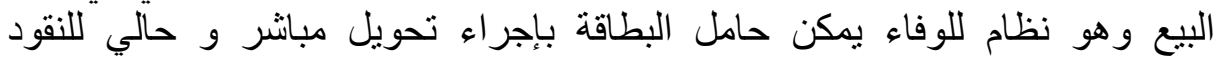
إلكترونيا من حساب صاحب البطاقة لحساب التاجر . لباء

\section{ب-بطاقة الخصم الثهري / بطاقة الحساب (carte de paiement fin mois)}

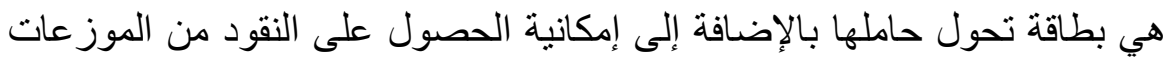

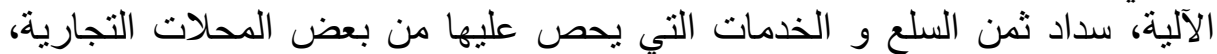

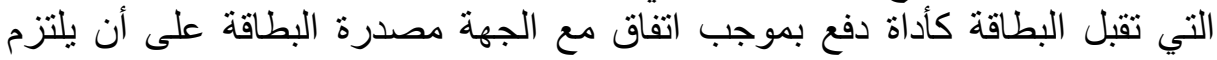
حامل البطاقة بسداد المديونية الناشئة عن استخدام البطاقة شهريا.

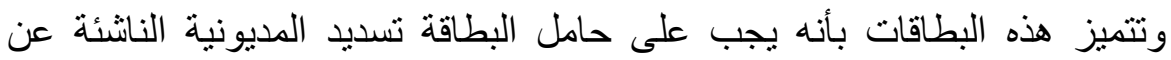
استخدامه للبطاقة فور استلامه لكثف الحساب الثهري، فالتسوية للمديونية الناشئة عن

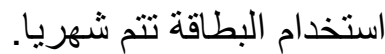
American express من أهم أمثلة هذه البطاقات بطاقة أمريكان إكسبريس لهُبان (9):(cartes de crédit) جطاقات الإنتمان 
يعتبر مصطلح بطاقة ائتمان "هو الاسم الثائع للتعبير عن أنواع بطاقات الدفع.

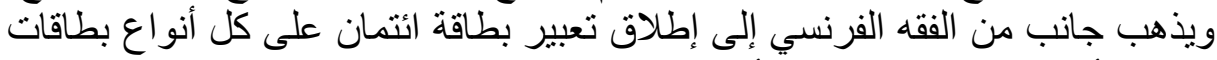

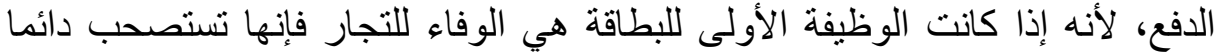

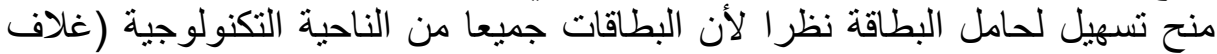
التي تعمل بنظام الخصم المباشر) تتطلب للخصم من حساب حامل البطاقة بعض لتص

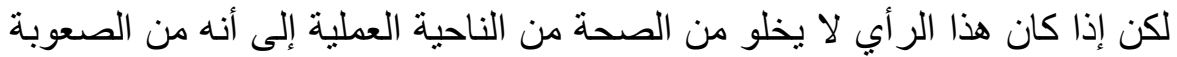

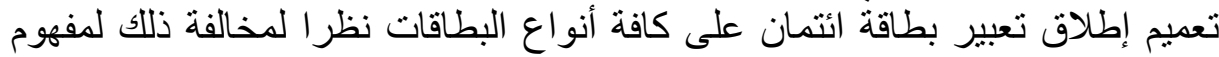

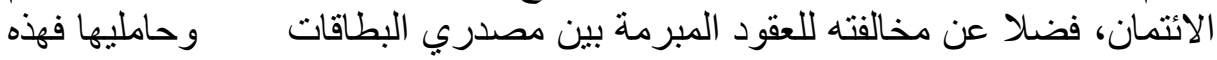

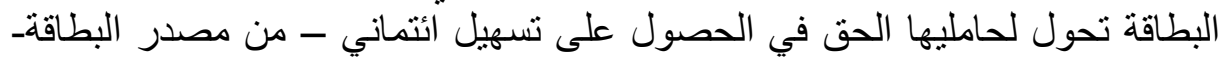

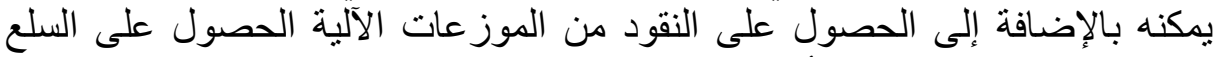

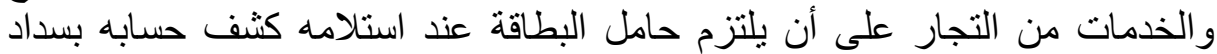

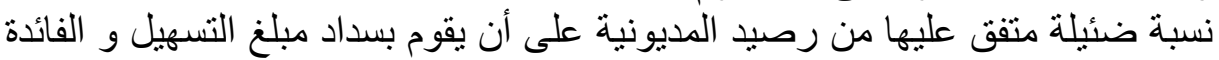
المتفق عليها في التاريخ المتفق عليه.

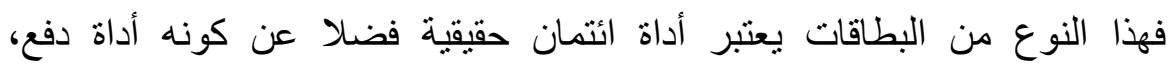

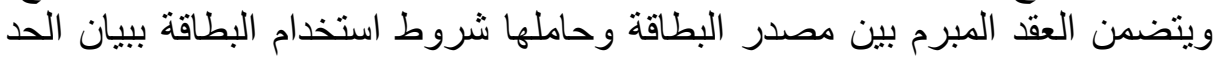

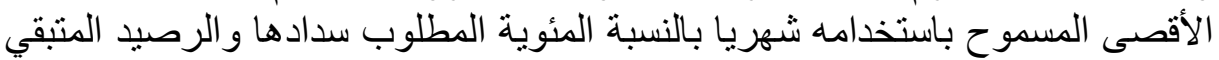

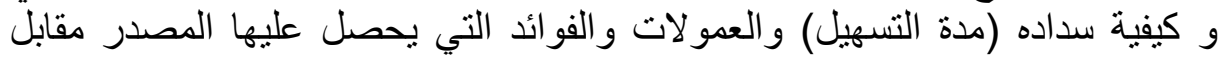
تقديم تسهيل لحامل البطاقة.

ثالثا: بطاقات ضمان الشيكات: (10) يمكن تعريف هذه البطاقة بأنها بطاقة تصدر ها البنوك و المؤسسات المالية الكبرى

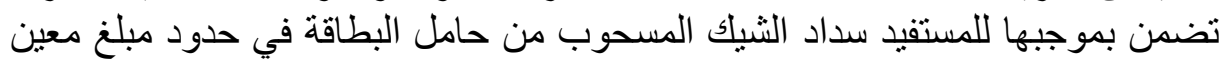
وفقا لشروط محددة.

من هذا التعريف يتضح لنا أن هذه البطاقات لا تعتبر أداة دفع لأنها تستخدم مرتبطة

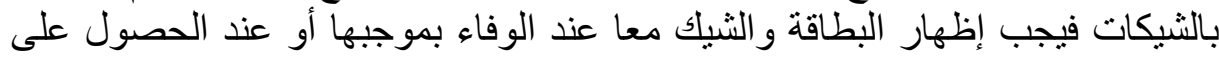
النقود من البنك و ذللك غلاف الخصم التي تستخدم كبديل للشيك. رابعا: العلاقات القانونية الناشئة عن إصدار بطاقة الدفع:

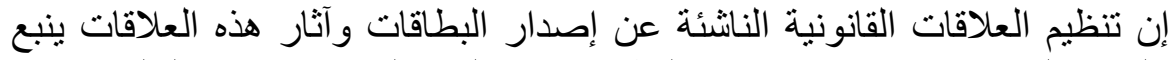

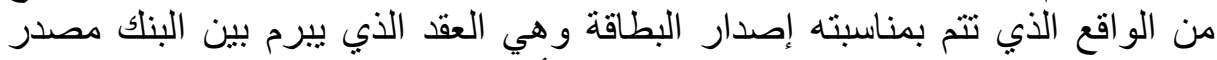

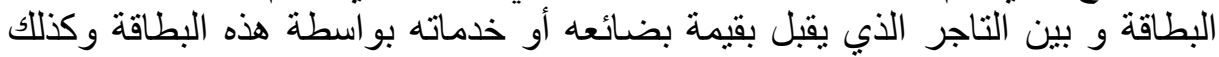
العقد الذي يبرم بين البنك و بين حامل البطاقة. (11) وسوف نتناول هذه العلاقات العقدية: 


\section{العلاقة الأولى: العلاقة بين البنك مصدر بطاقة الدفع وبين عميله:}

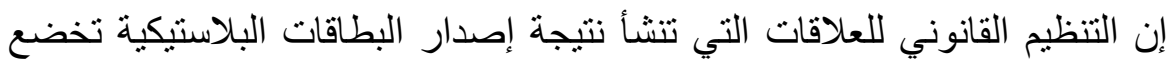

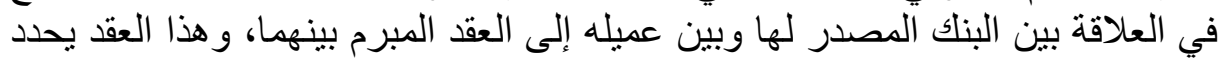
بدقة طرق استخدام البطاقة ومدتها والحد الأقصى من المبالغ المبل المباح استخدام البطاقة

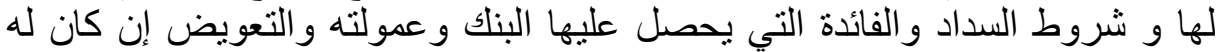

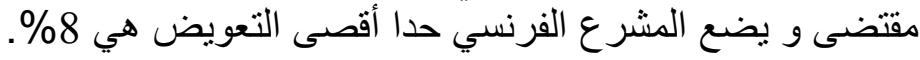

و غالبا ما يرتبط العقد بين البنلك وعملية بفتح حساب للعمبل يصب فيه فيه جميع

تعاملات الأخير في شأن وخصوص المقالبر البطاقة المسلمة إليه. (12)

ويتم العقد بين البنك مصدر بطاقة الدفع و بين العميل بايجاب يصدر من البنابه

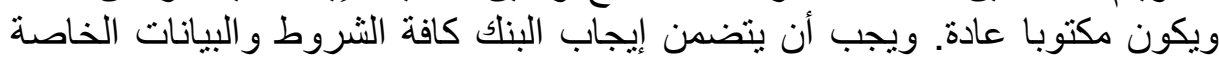

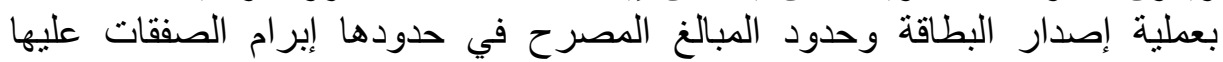
لصالح المحال التجارية.

كذلك يلتزم البنك بإيضاح جميع المحاذير وطرق الحفاظ على البطاقة لعميله

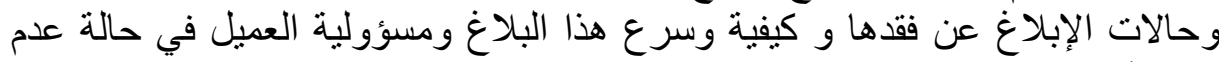
الإبناغ.

ويرسل البنك موافقته على تعاقد العميل وتكون الموافقة مكتوبة. على أنه غالبا ما باليا

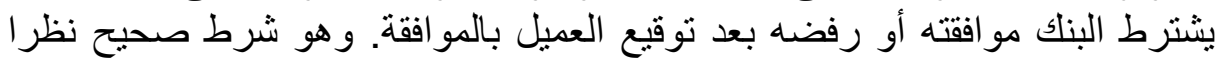
لابتناء العقد على الاعتبار الشخصي.

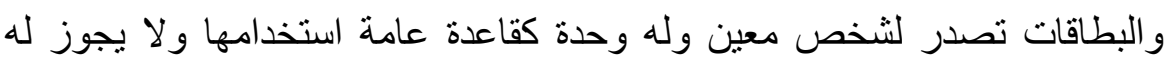

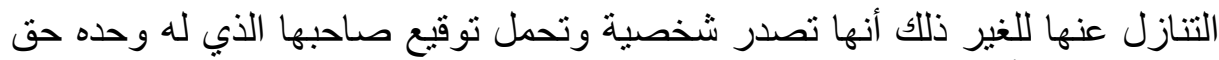

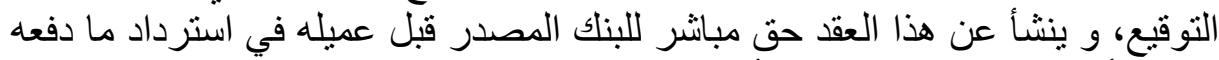

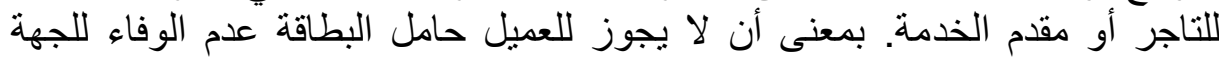

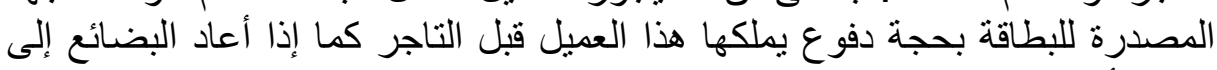

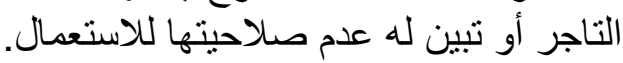

ويلتزم العميل بالوفاء بقيمة مشترياته أو تعاملاته مع البنك مصدر البطاقة إما فورا

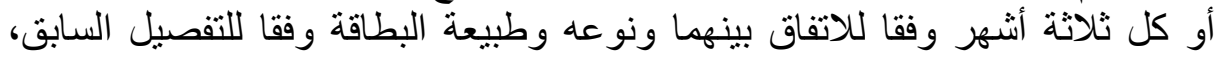

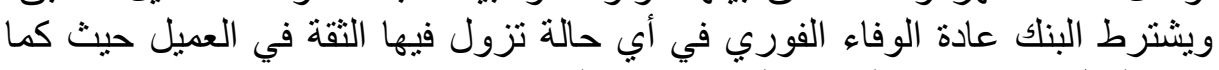

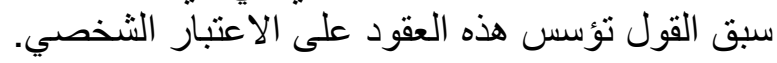

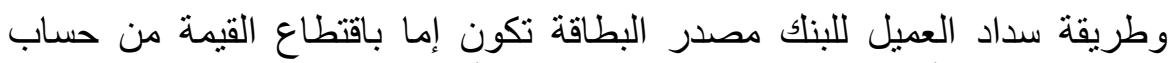

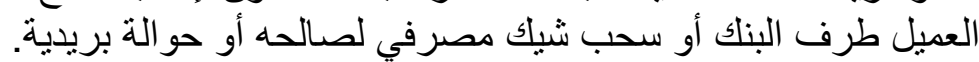

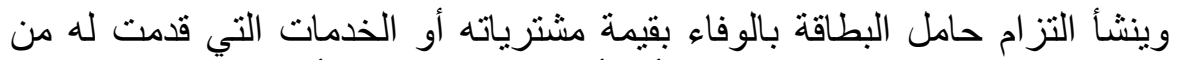
التاجر بناءا على توقيعه فو اتير الثراء أو تأدية الخدمة. بمعنى أنم توقئه أنيع العميل حامل 


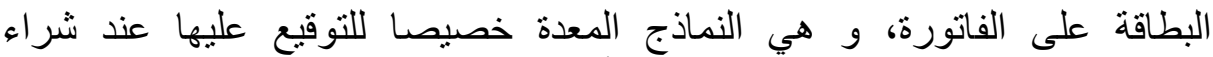

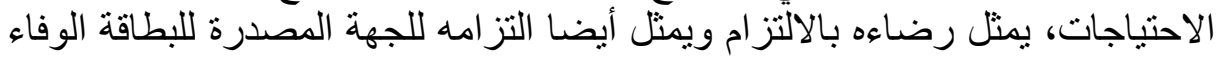

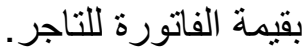

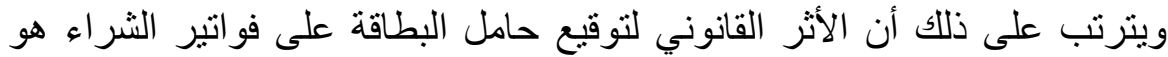

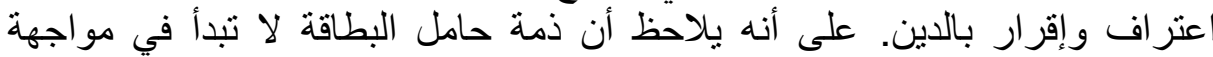

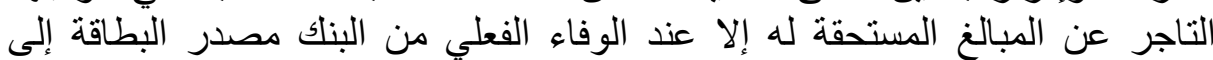

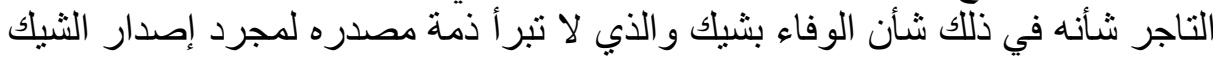
بل بالوفاء الفعلي للمستفيد منه.

وبذلك فإن استخدام البطاقة يعتمد في الواقع على نقل الأموال إلكترونيا بتذخل

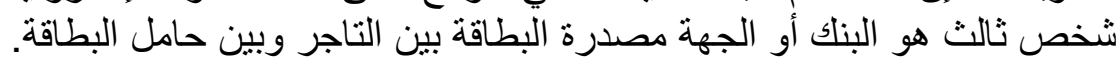

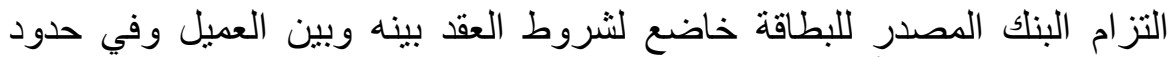

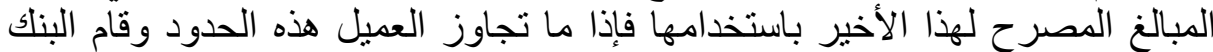

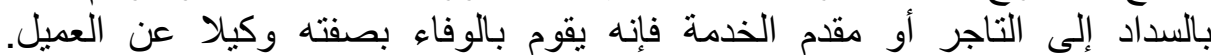

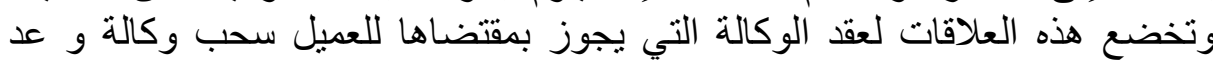

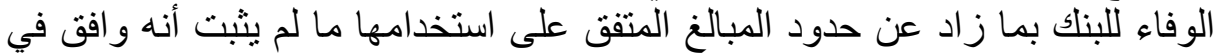
وقت مناسب على هذا الوفاء ولم يقم بإخطار البنلك بعدم رغبتها.

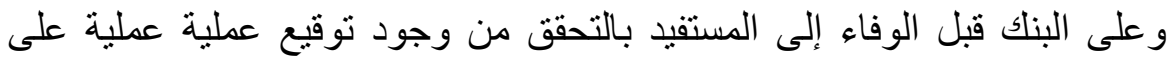

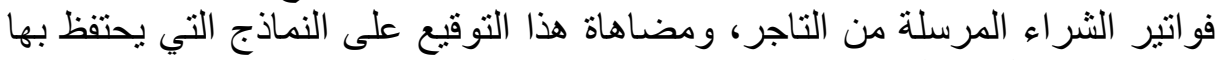

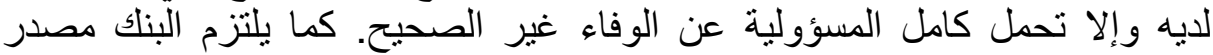
البطاقة بإرسال كثف حساب لعميله من وقت لآخر يفيد كيفية بيان حركة تعاملاته على الحساب.

و إذا حرر العميل شيكا بضمان البطاقة التزم البنك بالوفاء بقيمة الثيك طالما كان في حدود الائتمان المتفق عليه بين البنك و بين العميل محرر الثيك. أما إذا كانت قيمة الثيك تتعدى المبالغ المتفق على استخدام البطاقة في حدودها

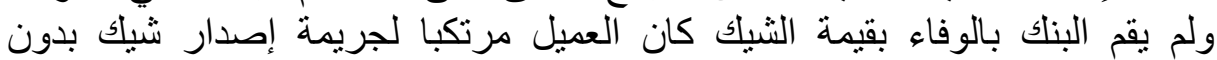
رصيد.

كما يلزم العميل بدفع قيمة الفو اتير وفقا للكثف الذي يرسل إليه من البناك بالإضافة إلى التز امه بالعمولة العمبل بلفع الئد وفقا للعقد.

و إذا فقدت البطاقة أو سرقت وجب على العميل إخطار الجهة المصدرة للبطاقة فور ا وبالطريقة المحددة في تعاقده معها، و إلا تحمل نتيجة التأخير أو عدم الخمل الإخطار.

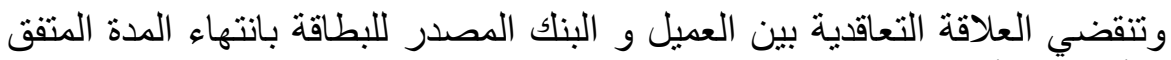
عليها أو رغبة أي من الطرفين في إنهائها. و لما كانت هذه العان العلاقة قائمة على الإعتبار 


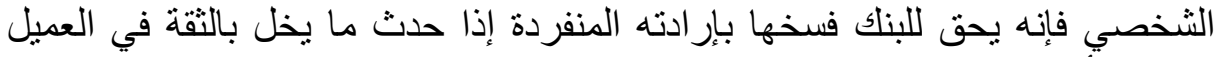
كإفلاسه أو صدور فرار بالحجر لابن فليه، كما تنقضي العلاقة بوفاة العميل.

ويظل البنك مصدر البطاقة ملزما بالوفاء بقيمة الفواتير المستخدمة على البطاقية

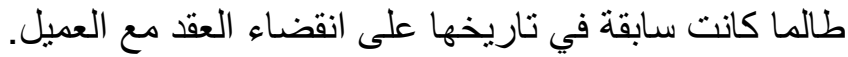

و إذا حدث واعترض العميل على كثوف الحساب المرسلة إليه من البنك مصدر الترة

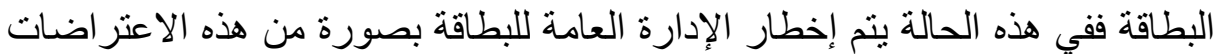

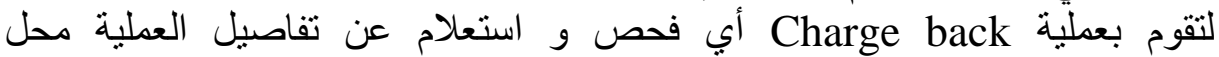
الاعتر اض، ويتحمل العميل مصاريف إعادة الفحص إذا ثبت عدم صحة الاعتر اض.

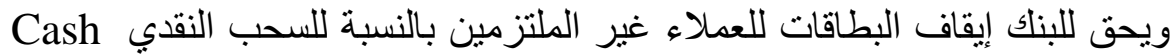

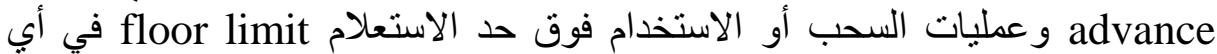

وبصفة عامة يمكن القول أن إيقاف التعامل على البطاقة يتم في الحالات الآتية: 1- فقد أو سرقة البطاقة و إبلاغ البنك بذلك.

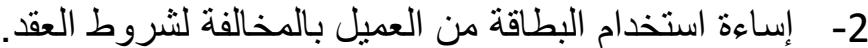
3- الحجز على حامل البطاقة. 4- تحويل حامل البطاقة للمساءلة القانونية لتوقفه عن سداد التزاماته قبل البنك أو رفع دعاوي بشأنها.

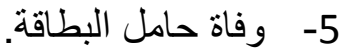

6- إيقاف التعامل مع العميل حامل البطاة البطة لأبي أسباب شرعية يراها البنك كصدور أحكام ضد العميل مخلة بالثرف.

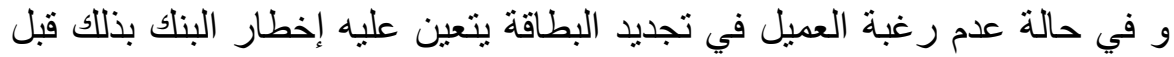

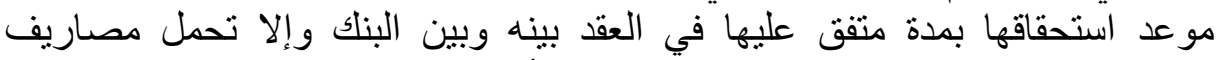

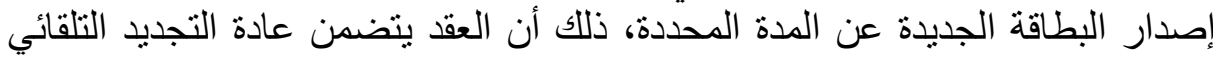
للبطاقة ما لم ير غب أب من الطرفين غير ذلك.

\section{العلاقة الثاتية: العلاقة بين البنك مصدر البطاقة و التاجر: (13)}

ينظم العلاقة بين البنك مصدر البطاقة والتاجر الذي يعلن على قبول التعامل بهذه

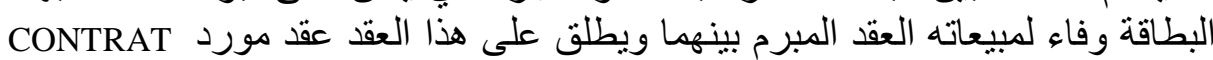
.FOURNISSEUR

ويتم التعاقد مع التاجر بناء على طلب يتقدم البنك مصدر البطاقة إلى المنظمة

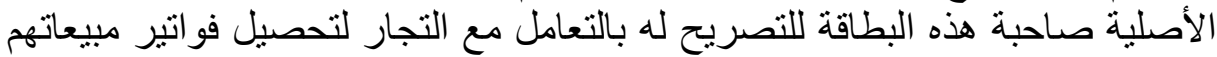

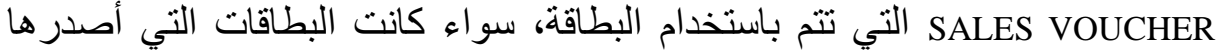

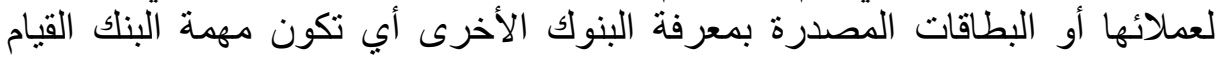

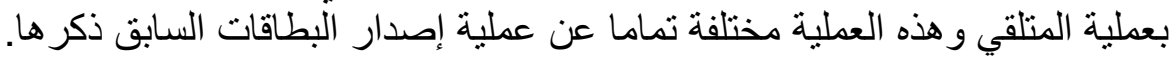


وبعد الحصول على مو افقة المنظمة للتعامل في هذا النشاط يقوم البنك بإبرام عقود مع التجار لقيامه بتحصيل الفو اتير لحسابهم. ويمكن للبنك التعامل على هذه الفو اتير SALES VOUCHER بعدة طرق مثل: أ- يقتصر دوره على مجرد تحصيل الفواتير لحساب التجار، مثل تحصيل

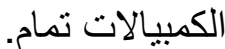

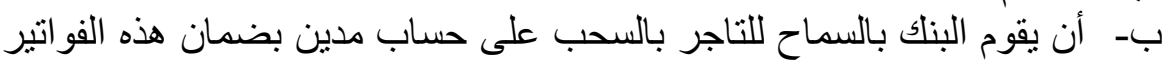

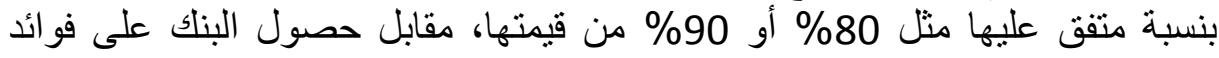
الأرصدة المدينة مثل الكمبيالات التأمين.

ج- أن يقوم البنك بشر اء هذه الفو اتير من التجار ويدفع كامل قيمتها لحساب التاجر

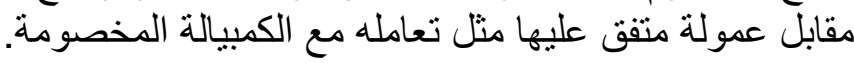

وجدير بالإشارة أن الفو اتير المشار إليها تختلف عن الكمبيالات لأنها مستحقة فعلا ولا تستحق بعد مدة كما هو الحال في الكمبيالات.

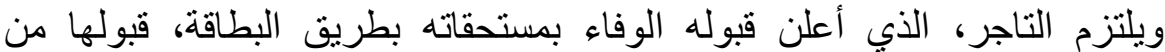

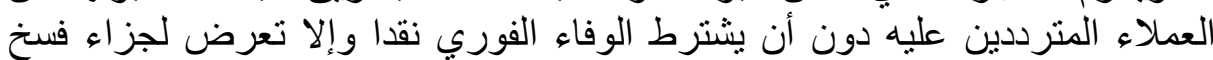
عقده مع البنك مصدر البطاقة، حيث يعد تعاقده و التز اماته حامل البطاقة الفئ.

على أنه يحق للتاجر أن يحتفظ بحقه في رفض استخدام البطاقة من حاملها في عقده مع البنك، على أن يكون ذللك بأسباب معقولة دون تعسف، و إلا فقد العقد بين

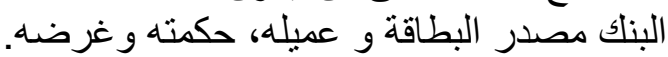

و العقد المبرم بين البنك مصدر البطاقة وبين التاجر المورد يرتب حقا شخصيا مستقلا ومجردا عن علاقة البنك بالعميل فالتاجر له الحق مباشر في اعنماد غير قابل

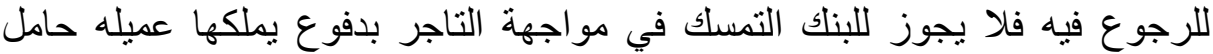

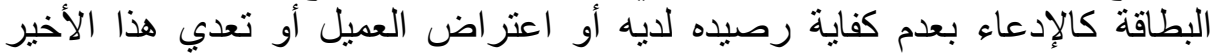

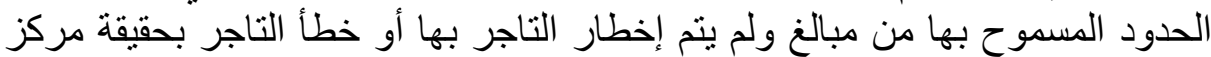

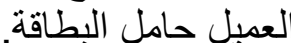

و إذا حدث و قام البنك بالوفاء للتاجر المورد بما يزيد على الاعتماد المخصص كان

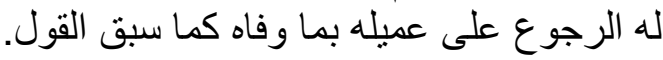
ومن المستقر غليه في فرنسا حق البنك في الحلول محل التاجر المورد قبل العميل حامل البطاقة وفقا للمادة (3/1251) مدني فرنسي التي تطابق المادة (1321) مدني

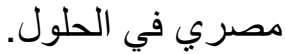

على أن التزام البنك مصدر البطاقة على هذا النحو قبل التاجر المورد مشروط بتقبد التاجر بالالتز امات التي يرفضها البنك قبله في خصوص التهات سداد هذه البطاقات وفقا بينهما، كما إذا كان البنك محددا لحد أقصى للمبآلغ التي تستخدم يوميا أو أسبوعيا 
للبطاقة من قبل العميل.

ويحكم تجاوز التاجر من عدمه مدى علمه بمركز العميل في البطاقة التي يحملها،

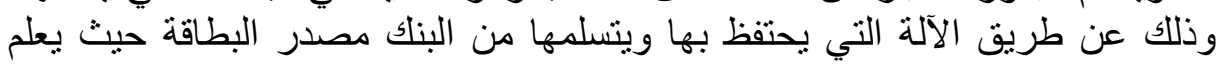

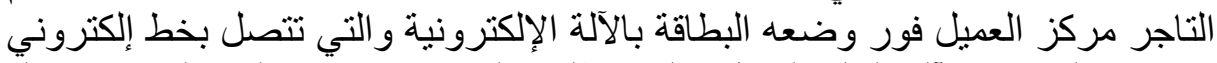

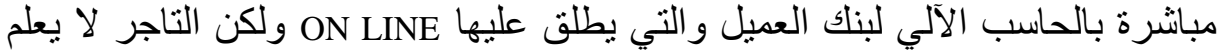

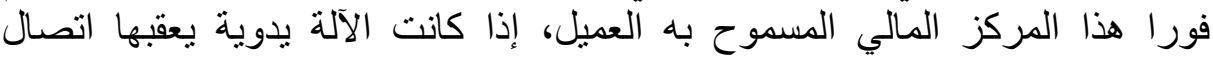
تليفوني بالبنك و هو ما يعرف ما يعرف بنظام OFF LINE كما سبق القول.

ويتم سداد التاجر من قبل البنك إما بالنقل المصرفي إلى حسابه أو بالقبد بهذه الحسابات طرف البنك.

كما على التاجر تنفيذ التزامه باتباع تعليمات البنك إليه مثل ختم الفاتورة و بصمة

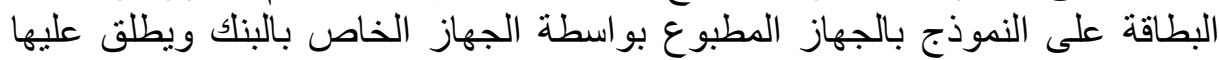

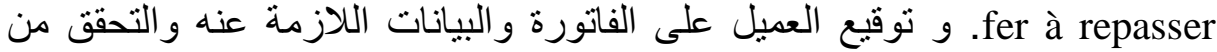
شخصه بدقة وبصفة خاصة الحدود المسموح التعامل عليها ومو اعيد إنهاء البطاقة.

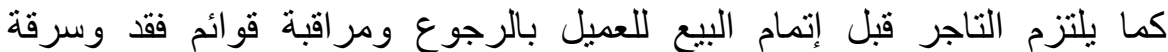

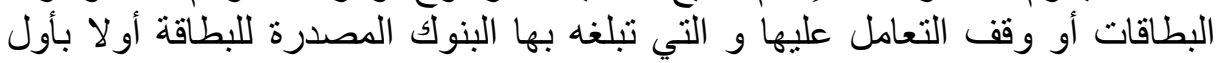

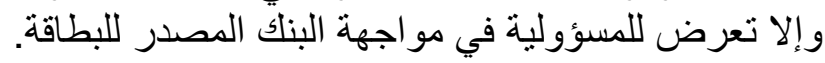
ولا يلزم التاجر باسترداد البطاقة من حاملها في أي من هذه الحالات.

هذا بالإضافة إلى التزام التاجر بدفع العدولة المتفق عليها للبنك نظير تقديم هذا الأخير لهذه الخدمات المصرفية.

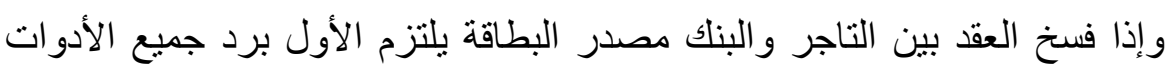

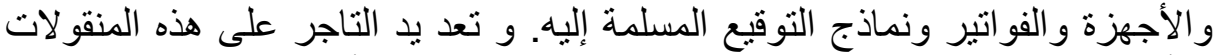
يد أمين يتعرض للمسؤولية الجنائية عند عدم المحافظة عليها أو الو عدم ردها.

\section{العلاقة الثالثة: العلاقة بين التاجر وعميل البنك (حامل البطاقة):(14)}

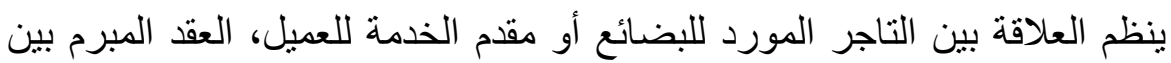
كل منهما والبنك مصدر البطاقة بالإضافة إلى العلاقة العقدية الجديدة بينهما وهي عقد التدان الثراء أو التزام المورد بتقديم الخدمة.

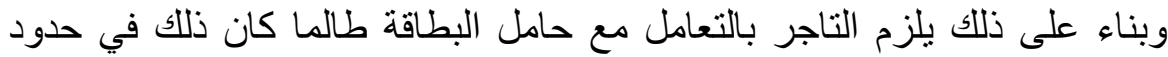

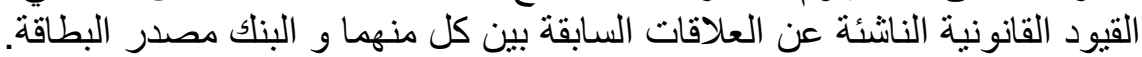
ويؤسس الفقه التزام التاجر المورد قبل البطاقة على أساس الاشتراط لمصلحة

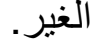
و لا ينقضي التزام العميل قبل التاجر لمجرد نوقيعه على الفاتورة المقدمة من التاجر 


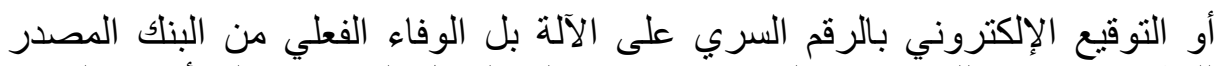

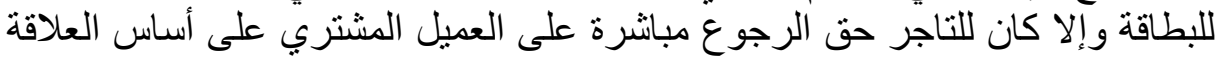

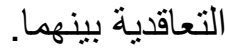
كما لا ينقضي التزام العميل نهائيا قبل البنك مصدر البطاقة إلا بسداده كما سبق

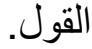

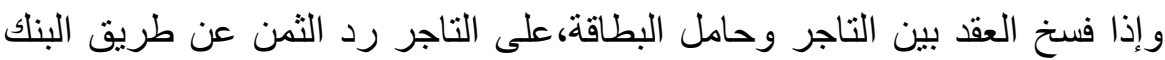
مصدر البطاقة الذي يعيد بدوره المبلغ إلى العميل أو يقيده بحساباته لديه.

\section{الطبيعة القانونية لنظام بطاقات الدفع الإلكترونية:}

في ضوء ما سبق يمكن القول أن بطاقة الدفع الإلكترونية لها طبيعة متميزة

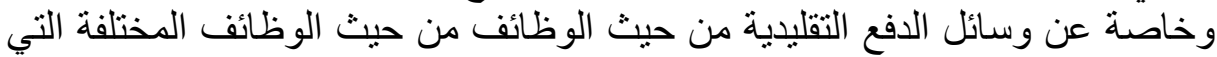
تقوم بها ومن حيث المزايا التي تحققها لحاملها و التي ترتبط بنظام الأداء بو اسطتها.

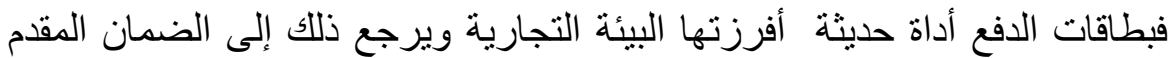

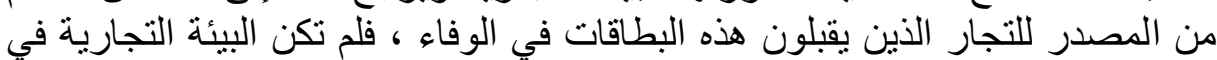

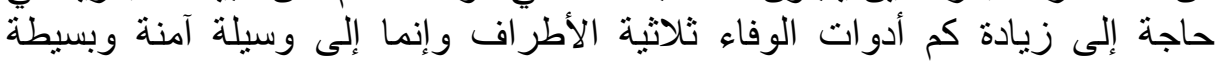

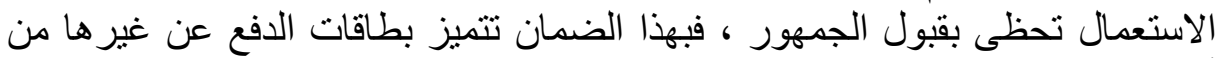
أدو ات الدفع التقليدية التئية

وبطاقات الدفع تقوم على علاقة ثلاثية الأطراف هم مصدر البطاقة وحاملها

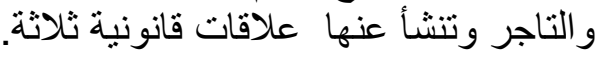

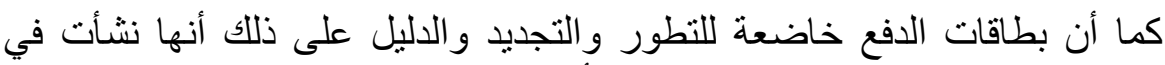

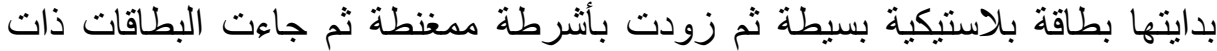
الدوائر الإلكترونية وقد صاحب هذا التطور في البطاقات تطور آلات البيع لدى التجار وكذلك تطور آلات الصرف وفرف

الخاتمة

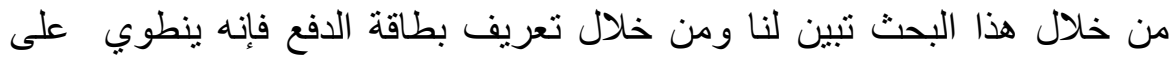

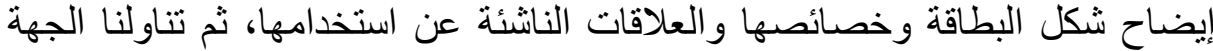

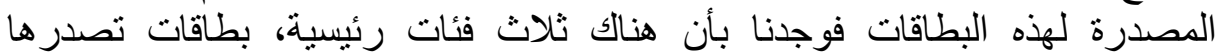

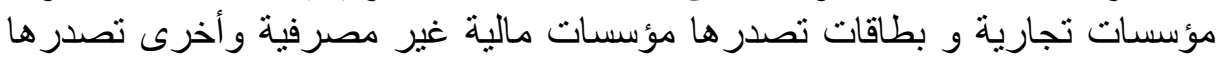
البنوك.

بعدها تناولنا العلاقات القانونية التي تنشأ عن نظام بطاقات الدفع ووجدنا ثلاثة

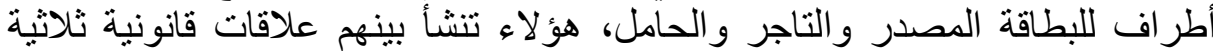
آثنار ها بناءا على العقود التي تبرم بمناسبة التعامل بها. 
العلاقة الأولى بين مصدر البطاقة و عميله ووجدنا بأن العقد هو المصدر الأول لهذه

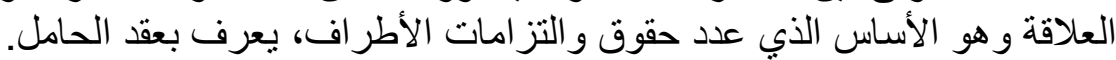
العلاقة الثانية بين البنك المصدر و التاجر الذي يقبل الوفاء بها، ووجدنا كذلك أن أن النائ هذا العقد هو الأساس لاستخدام البطاقة و مصدر لتنظيم العلاقة بينهما. ويعرف بعقد المورث أو عقد التاجر أو عقد الانضمام. ويترتب بموجبه التزامات متبادلة. ثم عرضنا العلاقة الثالثة بين حامل البطاقة والتاجر هذه الأخيرة تعتبر الهدف الرئيسي لنظام بطاقات الدفع.

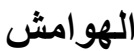

1- فايز نعيم رضوان، بطاقات الدفع الإلكتروني من الوجهة القانونية، دار النهضة

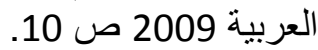

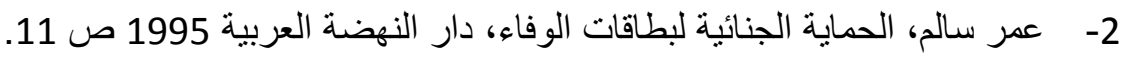

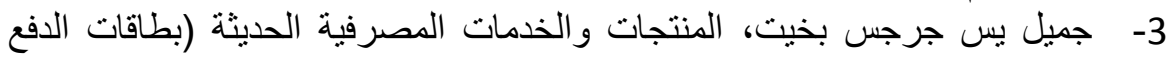
الإلكتروني) المعهد المصرفي جرجن 2001، ص الجم 7 وما بعدها.

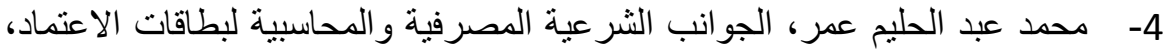
إيتر الك للنشر و التوزيع 1997 ص صديد 37. 5- كيلاني عبد الراضي محمود، النظام القانوني لبطاقات الوفاء و الضمان، دار النهضة

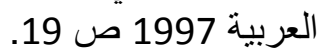

6- عبد الفتاح بيومي حجازي، النظام القانوني لحماية التجارة الإلكترونية، الكتاب

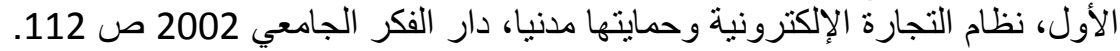
7- هدى شكري، نظم الدفع الحديثة في السوق المصنية الدرفي، المعهز المصري 1999

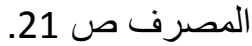

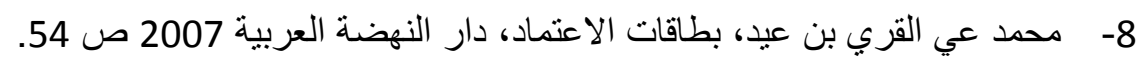

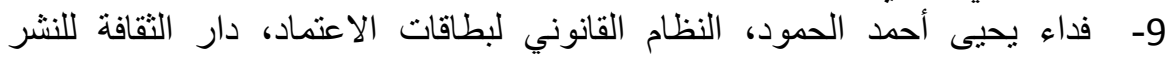

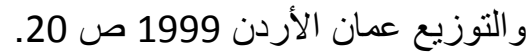
10- عية سالم عطية، بطاقات الدفع الإلكتروني، دار الفكر العربي 1999 ص 64. 


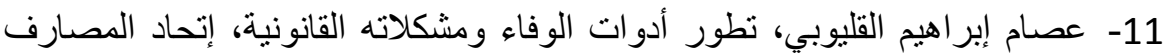

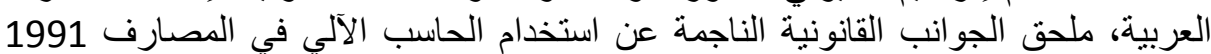

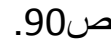

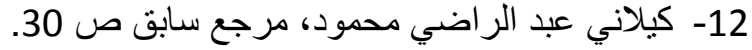

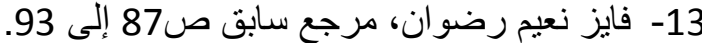

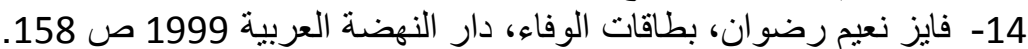

ــ الأمر رقم (10-10) المؤرخ 16-04-1990 المتعلق بالنقد و القرض الجريدة الرسمية

ـ الأمر رقم (11-11) المؤرخ 26-06-11-2011 لمتعلق بالنقد و القرض الجريدة الرسمية.16.

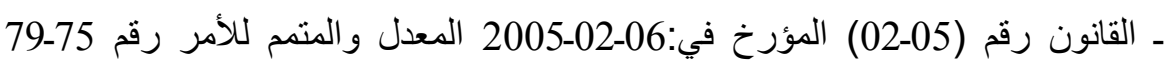
المؤرخ في:26-09-1975 المتضمن القانون التجاري الجريدة الرسمية العدد 11 ـ. 